\title{
The Hall Technique 10 years on: its effect and influence
}

\author{
R. R. Welbury ${ }^{1}$
}

In brief

Dental caries in early childhood can have a very significant effect not only on the oral health of young children but on their quality of life and that of their families. Added to this are the long-term infective risks to the host of untreated caries in primary teeth but also the risk of damage to successor permanent teeth. Traditional restoration of damaged primary teeth has been shown to have only moderate outcomes depending on the techniques and materials used and the ability of children to cooperate because of age or other factors. The Hall technique has outperformed other techniques in randomised clinical trials. In this Opinion Article I will take a look back at the Innes et al. paper, first published in this Journal in 2006, that introduced the Hall Technique and the subsequent scientific literature which provided us with high quality scientific evidence of the efficacy of the technique. I will evaluate how this new technique has affected the management of early childhood caries and hence its influence on wider oral and general health.

The prevalence of dental caries in British children is high with $31 \%$ of 5 -year-olds and $46 \%$ of 8 -year-olds having obvious dentinal decay experience. In the 5 -year-olds $4 \%$ had abscesses and $5 \%$ of the teeth were unrestorable. ${ }^{1}$ Unbelievably, over 66,000 young people in the UK had to have a general anaesthetic for the management of their dental disease in 2013-2014. ${ }^{2}$ Dental decay is the commonest reason for a general anaesthetic in this age group and the cost to the NHS is about $£ 34$ million per year. This is a national disgrace.

Even if the behaviour and cooperation for treatment in children was ideal, the restoration of their teeth would still be a technically demanding exercise due to the size and morphology of the primary teeth. If anyone who treats a lot of children was able to hope or dream of a new treatment for dental disease in children which might succeed where conventional treatments had failed, I would suggest that it would need to have the following properties:

'University of Central Lancashire, Preston. Correspondence to: Professor Richard Welbury Email: rwelbury@uclan.ac.uk

Refereed Paper. Accepted 30 January 2017

DOI: 10.1038/sj.bdj.2017.262

${ }^{\circ}$ British Dental Journal 2017; 222: 421-422
- Overall easier for the child (and parent) to cope with

- Quicker to complete

- Not requiring local anaesthetic

- Proven efficacy by randomised controlled trials

- Easy to teach to students and general practitioners.

The 'Hall Technique' originally pioneered by dental practitioner Norna Hall in response to an overwhelming amount of caries in the children under her care and subsequently taken up and tested scientifically by Evans, Innes and colleagues does exactly what it says on the tin. It ticks all the previously mentioned five points. We shouldn't be surprised because Dr Hall applied the science that she had been taught at dental school to her specific problem. The scientific evidence was available that glass ionomer cements bond to enamel and dentine, that bacteria denied of substrate and sealed into the tooth die and do not cause caries progression, and that a crown is the best way of producing an effective marginal seal. So the Hall Technique which utilises all those three principles is a truly biological technique borne out of our increasing scientific understanding of the caries process.
Evans, Innes and colleagues over the last ten years have provided us with high quality scientific evidence of the efficacy of the technique and specifically an RCT of five years duration. ${ }^{3}$ There can be no argument as to its efficacy. I am disappointed at scientific meetings when colleagues who teach their students to appraise the literature and decide to treat accordingly upon the evidence base seem to have selective blindness when it comes to the Hall Technique. They clearly are not practising what they preach. It could also be argued that by ignoring the attributes of the Hall Technique they are subjecting their patients to longer and more demanding treatment which has no proven improved efficacy.

Recent work by Page and colleagues ${ }^{4}$ in New Zealand has endorsed previous findings in the UK of the high acceptability of the technique to parents and children. ${ }^{5}$ In the New Zealand study crowns were fitted by dental therapists on primary molars with a mixed methods study design approach using qualitative and quantitative analysis. One focus group was conducted and ten thirty-minute phone interviews were undertaken with parents of children. An inductive approach was used to analyse the qualitative data and information was arranged into several categories based on the key themes 
which arose. Children treated with the Hall Technique were asked immediately after treatment whether they had enjoyed their visit to the clinic that day and nearly $90 \%$ responded positively. Common themes were found with regard to appearance, pain, the procedure and general questions on acceptability but overall there was a high degree of acceptance among both parents and children for the technique.

The Hall technique was introduced into the undergraduate paediatric dentistry curriculum in UK dental schools before 2010 and clinical teachers have witnessed an increase in student confidence and use of stainless steel crowns as a result. ${ }^{6}$ It is also being taught on dental therapist training courses with similar success. ${ }^{7}$

It is important to stress that the Hall Technique is being taught as an alternative to conventional preparation and not as a primary treatment for all patients. There are still clinical indications for conventionally-placed stainless steel crowns and there are excellent outcomes reported in specialist practice at ten years duration, albeit case series designs and not RCT. ${ }^{89}$ One recent retrospective study in the USA evaluated the clinical and radiographic success of stainless steel crowns used to restore primary molars with caries lesions, placed by both traditional technique (complete caries removal and tooth reduction) and the Hall Technique (no caries removal, no crown preparation and no use of local anaesthetic) and showed similar success rates. ${ }^{10}$

The common findings in quantitative studies involving undergraduate dental and therapy students is that the Hall Technique is an acceptable procedure giving favourable treatment experiences for operator and patient.

Despite the positive experiences of the Hall Technique during recent undergraduate training there is evidence of a reluctance by older practitioners to use it in practice. However, the study by Taylor ${ }^{11}$ shows how the enthusiasm of a vocational trainee to use the Hall Technique (learnt whilst an undergraduate), can lead to a change in practice restorative policy.

One often used reason for not using the Hall Technique is that it will increase the occlusal vertical dimensions. In fact there is evidence that the occlusion equilibrates after 30 days and there is no evidence of any long term issue. ${ }^{12,13}$ Similarly there is no evidence that preformed metal crowns placed without prior tooth reduction will have any influence at all on future spacing considerations in the developing dentition.

The Hall Technique has made a huge difference to children, parents and clinicians in the management of caries in the primary dentition. It has given us a biological solution to a significant national and international problem.

Our child safeguarding legislation in the UK is built around the five major principles outlined in the Children Act 1989: ${ }^{14}$

- The welfare of the child is paramount

- There is parental 'responsibility' and not 'right'

- 'No order' principle

- No delay in court proceedings

- Corporate responsibility and partnership across local authorities and between local authorities and other organisations.

Three of these principles are directly applicable to our discussion about the Hall Technique. The welfare of the child is paramount. Caries which can cause pain and infection in the primary dentition should not be left. The Hall Technique gives us an extra technique in our armamentarium as clinicians to achieve treatment relatively atraumatically. The 'No order' means that any intervention you carry out must not leave the child in a worse position than if you hadn't intervened. Evidence has been presented to show that the Hall Technique is conclusively of benefit to the child and has shown no harmful effects. Finally, it is the duty of every dental professional to help to reduce the burden to children and parents of caries in the primary dentition. We need to be more powerful advocates of the Hall Technique. It is not enough to acknowledge the sound scientific principles on which it is based, but it is time to 'trust' its efficacy and use it more.

1. Children's Dental Health Survey 2013. Executive Summary: England, Wales and Northern Ireland. Health and Social Care Information Centre, UK, 2015.

2. Deery C, Owen J, Welbury R, Chadwick B. Dental caries in children and the level of repeat general anaesthetics for dental extractions. A national disgrace. Dent Update 2015; 42: 305-306.

3. Innes N P, Evans D J P, Stirrups D R. Sealing caries in primary molars: randomized control trial, 5 year results. J Dent Res 2011; 90: 1405-1410.

4. Page LA F, Boyd D H, Davidson S E, McKay S K, Thomson W M, Innes N P. Acceptability of Hall Technique to parents and children. N Z Dent J 2014; 110: 12-17.

5. Bell S, Morgan A, Marshman Z, Rodd H. Child and parental acceptance of preformed metal crowns. Eur Arch Paediatr Dent 2010: 11: 218-224.

6. Gilchrist F, Morgan A G, Farman M, Rodd H D. Impact of the Hall Technique for preformed metal crown placement on undergraduate paediatric dentistry experience. Euro J Dent Educ 2012; 17: e10-e15.

7. Jackson G. Placement of preformed metal crowns on carious primary molars by dental hygiene/ therapy vocational trainees in Scotland: A service evaluation assessing patient and parent satisfaction. Prim Dent J 2015; 4: 46-51.

8. Roberts J, Attari N, Sherriff M. The survival of resin modified glass ionomer and stainless steel crown restorations in primary molars, placed in specialist paediatric dental practice. Br Dent J 2005; 198: 427-431.

9. Roberts J, Sherriff M. The fate and survival of amalgam and stainless steel crown molar restorations placed in a specialist paediatric dental practice. $\mathrm{Br}$ Dent J 1990; 169: 237-244.

10. Ludvig K H, Fontana M, Vinson L A, Platt J A, Dean J A. The success of stainless steel crowns placed with the Hall Technique. JADA 2014; 145: 1248-1253.

11. Taylor $\mathrm{G}$. a change in practice protocol: preformed meta crowns for treating non-infected carious primary molars in a general practice setting: A service evaluation. Prim Dent J 2015; 4: 22-26.

12. van der Zee $V$, van Amerongen WE. Influence of preformed metal crowns (Hall Technique) on the occlusal vertical dimension in the primary dentition. Eur Arch Paediatr Dent 2010; 11: 225-227.

13. So D, Evans D J P, Borrie F et al. Measurement of Occlusal Equilibration Following Hall Crown Placement. J Dent Res 2015; 94 (Spec Iss A). Abstract No 0080; 2015. IADR, Boston US.

14. Children Act 1989. Available at www.legislation.gov.uk/ ukpga/1989 (accessed March 2017) 